\title{
Perbaikan Sistem Kontrol pada Filter Weak Ammonium Nitrate Solution
}

\author{
Julianta Wahyu Utama ${ }^{*}$, Zaini ${ }^{2}$ \\ ${ }^{1,2}$ Program Studi Teknik Elektro, Sekolah Tinggi Teknologi Bontang \\ e-mail:kamajaya83@yahoo.com ${ }^{1}$; zaini.math@gmail.com²
}

\begin{abstract}
Filter Ammonium Nitrate Solution consists of a filter element, gear motors filter, filter unit, shut-off drain valve and pressure gauge which are controlled from the Local Control Panel (LCP) using a conventional control circuit contactors and relays. Currently, the filter is disabled from operation because the control system while operating i.e. sequence fail/ order of work (especially when auto), feedback indication pressure gauge, and control monitor doesn't work properly is failure.. This research, the control system of performance filter on manual and auto that will be simulated using simulation software PLC Siemens step 7. The results shows that at the initial conditions of manual control system performance has no problem; however, when it works on auto performance, the control system failure due to relay timer Tl as the initial auto start does not exist in the control circuit. Having analized by entering the interlock pressure transmitter signal as the auto start initial then designing a new control system using Programmable Logic Control (PLC) shows that the problems of the control system performance can be totally solved to perform sequence filtering, cleaning and draining both on manual and auto control.
\end{abstract}

Keywords : Filter Ammonium Nitrate Solution, Manual, Auto

\begin{abstract}
Abstrak
Filter Ammonium Nitrate Solution ini terdiri dari elemen filter, motor gear filter, filter unit, shut-off drain valve, pressure gauge yang semuanya dikontrol dari Local Control Panel (LCP) menggunakan rangkaian kontrol konvensional kontaktor dan relai-relai. Saat ini, filter dalam keadaan dinonaktifkan dari pengoperasiannya disebabkan karena pada saat dioperasikan mulai dari terputusnya sequence/ urutan kerja (terutama pada saat auto), feedback indikasi pressure gauge sampai pada monitoring sering mengalami kegagalan system kontrol. Pada penelitian ini, kinerja sistem kontrol filter pada saat manual dan auto disimulasikan menggunakan simulation software PLC Siemens step 7. Hasil penelitian menunjukkan bahwa awal kinerja sistem kontrol pada saat auto mengalami kegagalan yaitu relai timer T1 sebagai inisial auto start tidak ada dalam rangkaian kontrol. Hasil Perbaikan yang dilakukan dengan cara menginputkan interlock pressure transmitter signal sebagai inisial auto start dan merancang sistem kontrol yang menggunakan Programmable Logic Control menunjukkan bahwa permasalah kinerja sistem kontrol dapat diatasi secara keseluruhan untuk melakukan sequence filtering, cleaning dan drain/ flushing baik pada saat manual maupun auto
\end{abstract}

Kata kunci : Filter Ammonium Nitrate Solution, Manual, Auto

\section{Pendahuluan}

\subsection{Latar Belakang Masalah}

Ammonium Nitrare Solution Plant memiliki sistem kontrol yang digunakan untuk mengontrol filter weak ammonium nitrate solution, level concentrator unit, ammonium nitrate liquior unit dan strenght analyser Ammonium Nitrate Solution sehingga dihasilkan produk akhir berupa ammonium nitrare solution dengan konsentrasi 60-63\% $\frac{w}{w}$, pH 5 sampai dengan 6.5, Total Organic
Content maksimal $100 \mathrm{ppm}$ dan Turbidity (tingkat kekeruhan) maksimal 1000 NTU (Nephelo metric Turbidity Unit ) [1].

Filter weak ammonium nitrate solution ini dipasang pada jalur masukan ammonium nitrate solution dan mempunyai fungsi utama untuk menyaring partikel anorganik yang terkandung didalam weak ammonium nitrate solution dengan konsentrasi 10-30\% sebelum dinaikkan konsentrasinya menjadi 60-63 \% di concentrator unit [2]. Filter ini terdiri dari 
elemen filter, motor gear filter, filter unit, shut-off drain valve, pressure gauge yang semuanya dikontrol dari Local Control Panel (LCP) menggunakan rangkaian kontrol konvensional kontaktor dan relai-relai.

Filter weak ammonium nitrate solution dalam istilah manufakturnya sering disebut sebagai MAHLE Metal-Edge filter, filter ini didesain untuk menyaring cairan ataupun pasta dengan kekentalan maksimal yang diijinkan sampai dengan $500.000 \mathrm{mPa}$ [2]. Proses filtrasi/penyaringan tidak menggangu proses produksi dan filter ini didesain dapat beroperasi pada kontrol auto maupun manual.

Pada aplikasi di Ammonium Nitrate Solution Plant, filter weak ammonium nitrate solution berfungsi sebagai penghancur, penyaring dan pemisah gumpalan kotoran organik dan anorganik yang tercampur di weak ammonium nitrate solution [2]. Penyaringan weak ammonium nitrate solution ini sangat diperlukan sebelum memasuki proses pemekatan di Concentrator.

Pada saat ini filter di non-aktifkan dari pengoperasiannya dikarenakan sering mengalami kegagalan sistem kontrol pada saat dioperasikan mulai dari terputusnya sequencel urutan kerja (terutama pada saat auto), feedback indikasi pressure gauge maupun monitoring kontrol yang kurang maksimal.

\subsection{Perumusan Masalah}

Permasalahan dalam penelitian ini mencakup dua hal yaitu (1) apakah penyebab kegagalan sistem kontrol filter weak ammonium nitrate solution pada saat dioperasikan? dan (2) bagaimana hasil analisa perbaikan sistem kontrol filter weak ammonium nitrate solution?

\section{Metode Penelitian}

\subsection{Prinsip Kerja Eksisting Sistem Kontrol Filter Secara Manual dan Auto}

Prinsip kerja secara manual dalam sistem kontrol filter pada penelitian yang digunakan adalah

1. Power utama 3 fasa ( $400 \mathrm{VAC} / 50 \mathrm{~Hz}$ ) Q1 dan power supply rangkaian kontrol (220
VAC/ $50 \mathrm{~Hz}$ ) Q3 dalam keadaan menyala ditandai dengan rectifier AC/DC sebagai power supply $24 \mathrm{VDC}$ dan lampu indikasi power kontrol on (H1) akan hidup

2. Ketika Hand Switch S1 (HS 34101) diposisikan manual dan tombol push button start manual flush sequence S4 (HS 34102) ditekan maka coil timer one shot T3 akan mendapatkan power $220 \mathrm{~V}$ AC dan akan aktif selama 36 detik

3. Pada waktu bersamaan coil relai bantu timer one shot R2 dan lampu indikasi manual sequence flush $\mathrm{H} 4$ akan aktif/ energized secara bersamaan.

4. Pada saat coil relai bantu timer one shot R2 energized maka kontak normally open R2 akan closed kemudian akan mengalirkan tegangan $220 \mathrm{~V}$ AC untuk mengaktifkan kontaktor utama K1 sehingga motor gear filter akan running dan lampu indikasi motor running $\mathrm{H} 2$ akan hidup. Ini artinya proses cleaning sedang berlangsung selama 36 detik. Pada proses cleaning ini, filter dibersihkan menggunakan mekanik scapper.

5. Ketika kontak normally open R2 closed secara bersamaan coil timer on delay T2 mendapat tegangan $220 \mathrm{~V}$ AC dan kontakkontaknya akan energized dengan on delay time 8 detik

6. Setelah on delay selama 8 detik, kontak normally open T2 akan closed sehingga coil valve control auxiliary relai R3 mendapat tegangan $220 \mathrm{~V}$ AC dan kontak normally open akan menutup

7. Pada kondisi kontak normally open dari R3 menutup, maka tegangan 24 VDC akan mengalir ke shut off valve XV 32063 dan mengaktifkan proses drain/ flushing. Proses drain/ flushing ditandai dengan lampu indikasi H3 hidup dan shut off valve dalam kondisi terbuka. Proses ini berlangsung selama 24 detik.

Sedangkan kerja filter dalam kondisi auto dengan mengoperasikan setiap sequence kerja dengan cara auto command. Pada saat auto, command start dari filter dimulai dari memposisikan selector switch (S1) pada posisi 
auto dan selanjutnya sequence filter akan running auto. Sequence auto berhenti sampai coil R1 energized dan coil T1 sebagai inisial auto start tidak ada dalam rangkaian kontrolnya.

\subsection{Perancangan Sistem}

\subsubsection{Pemasangan Pressure Transmitter}

Pemasangan pressure transmitter pada vessel filter 32F005 dilakukan dengan melepas pressure gauge terpasang kemudian memasang dengan pressure transmitter jenis diapraghma ini pada nozzle yang sama. Pressure indikator inlet vessel PI 34121 diganti dengan pressure transmitter PIT 34121 terpasang pada nozzle nomor 4 dan pressure indikator outlet vessel PI 34120 diganti dengan pressure transmitter PIT 34120 terpasang pada nozzle nomor 5. Proses koneksi kedua pressure transmitter menggunakan G1/2 DIN 16288 male [3]. Wiring koneksi menggunakan sistem 2 wire, 4 - $20 \mathrm{~mA} \mathrm{DC}$ Output dengan digital communication. Penentuan Range Kalibrasi \& Span Pressure Transmitter dapat dilihat pada tabel 1

Tabel 1 Hasil perhitungan konversi pressure input dan

\begin{tabular}{cc}
\multicolumn{2}{c}{ analog output sinyal } \\
\hline $\begin{array}{c}\text { Input Pressure } \\
(\mathrm{kPa} \mathrm{g})\end{array}$ & $\begin{array}{c}\text { Sinyal output } \\
(\text { dalam mA })\end{array}$ \\
\hline 0 & 4 \\
\hline 25 & 8 \\
\hline 50 & 12 \\
\hline 75 & 16 \\
\hline 100 & 20 \\
\hline
\end{tabular}

Perhitungan pressure differential didapatkan dari pembacaan aktual sisi inlet (PIT 34121) dan sisi outlet (PIT 34120) dari formulasi dibawah ini :

$$
\Delta P=P_{\text {inlet }}(P I T 34121)-P_{\text {outlet }}(P I T 34120)
$$

Penggunaan pressure differential sebagai trigger inisial start auto pada saat filter diposisikan auto. Batas maksimal dari differensial pressure adalah $30 \mathrm{kPa}$ g yang berarti filter elemen pada kondisi kotor [2]. Ketika differential pressure membaca minimal
$30 \mathrm{kPa}$ g maka sequence akan berjalan secara auto untuk cleaning dan draining. Sistem auto inilah yang akan dirancang sebagai langkah perbaikan sistem kontrol secara keseluruhan dari filter weak ammonium nitrate solution.

2.3.2. Perbaikan sistem kontrol pada saat Auto dan Manual

Rancangan Programmable Logic Control (PLC) pada pada saat auto operasi, start atau tahapan persiapan mengopersikan filter dimulai dengan memastikan local control panel pada kondisi siap baik dari rangkaian daya maupun kontrolnya dan valve inlet maupun valve outlet dalam kondisi terbuka. Tahapan selanjutnya, memposisikan selector switch (S1) pada auto operasi kemudian tahapan filtering dimulai, dimana ammonium nitrate solution akan difilter/ disaring secara langsung oleh metal edge filter. Ketika differential pressure ( $\mathrm{P}$ ) sudah mencapai lebih dari atau sama dengan $30 \mathrm{kPag}$ maka sistem kontrol akan menginisialisasi tahapan proses cleaning secara auto ditandai dengan motor gear filter running secara automatis, proses cleaning akan berhenti secara automatis ketika differential pressure ( $\mathrm{P}$ ) kurang dari atau sama dengan $10 \mathrm{kPag}$ ditandai dengan motor gear filter berhenti secara auto. Setelah proses cleaning selesai, sistem kontrol akan melakukan tahapan proses drain/ flushing secara auto selama 7 detik. Dengan berakhirnya tahapan proses drain/ flushing maka satu sequence kerja filter dinyatakan selesai. Perhatikan gambar 1 berikut. 


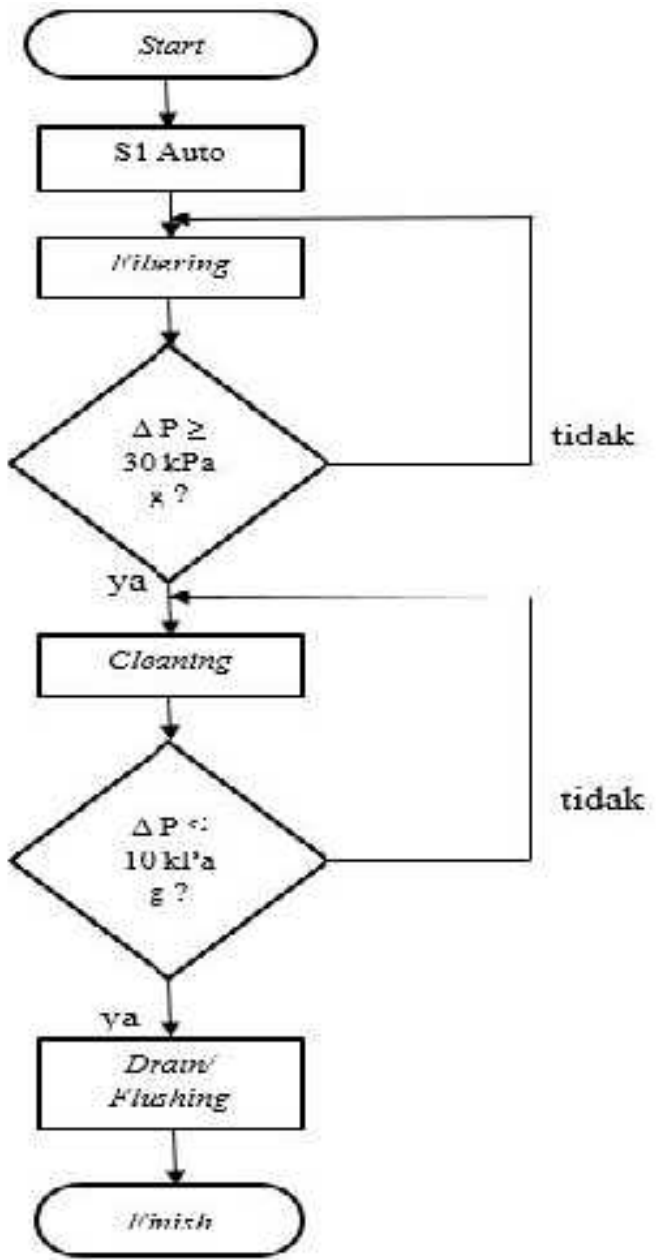

Gambar 1 Diagram alir pada auto operasi

Pada saat manual, semua sequence kerja filter dimulai dan diakhiri secara manual operasi dari local control panel. Start atau tahapan persiapan mengopersikan filter dimulai dengan memastikan local control panel pada kondisi siap baik dari rangkaian daya maupun kontrolnya dan valve inlet maupun valve outlet dalam kondisi terbuka. Tahapan selanjutnya dengan memposisikan selector switch (S1) pada manual operasi. Pada saat differential pressure ( $\mathrm{P}$ ) terbaca lebih dari atau sama dengan $30 \mathrm{kPag}$, tahapan proses cleaning dimulai dengan memposisikan selector switch (S2) pada posisi on secara manual dari local control panel. Pada saat differential pressure ( $\mathrm{P})$ terbaca kurang dari atau sama dengan $10 \mathrm{kPag}$, tahapan proses cleaning diakhiri dengan memposisikan selector switch (S2) pada posisi off secara manual dari local control panel. Setelah tahapan proses cleaning selesai, tahapan selanjutnya adalah drain/ flushing dengan mengoperasi selector switch (S3) open dan close secara manual dari local control panel. Perhatikan gambar 2 berikut.

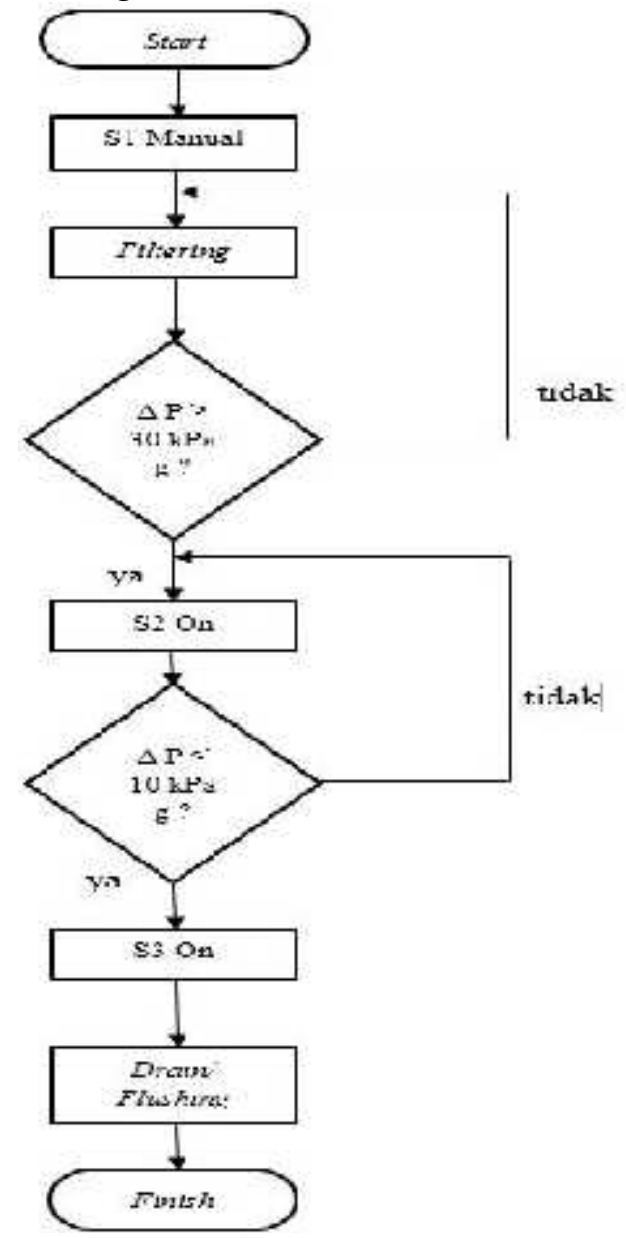

Gambar 2 Diagram alir pada manual operasi

\subsubsection{Desain perangkat lunak dan pengalamatan input-output}

Desain rangkaian komponen menggunakan PLC Siemens S7-300, hardware konfigurasi PLC terdiri dari: Power Supply (PS) 24 VDC/ 5A, CPU 315-2DP modul, sinyal module digital input (DI) 16 x 24 VDC, sinyal module digital output (DO) 16 x 24 VDC dan sinyal modul analog input (AI) 4 x 12 Bit [4]. Konfigurasi hardware dengan PLC ditunjukkan pada gambar 3. 


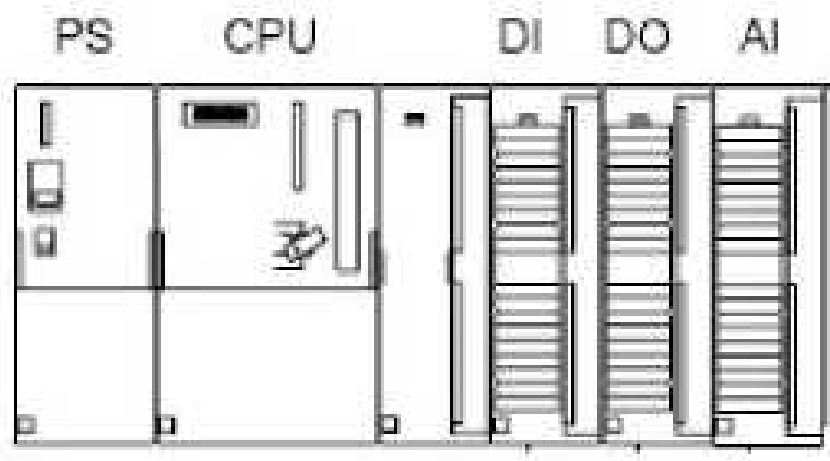

Gambar 3 Konfigurasi Hardware PLC S7 300

Tabel 2. Alamat Digital Input PLC

\begin{tabular}{clc}
\hline No & Deskripsi Digital Input & Alamat \\
\hline 1 & Auxiliary contact MCB 3 fasa (Q1) & I 0.0 \\
\hline 2 & Auxiliary contact Thermal Overload (Q2) & I 0.1 \\
\hline 3 & Emergency Switch (S5) & I 0.2 \\
\hline 4 & Selector Switch Auto/Manual posisi (S1) & I 0.3 \\
\hline 5 & Motor on push button (S2 & I 0.4 \\
\hline 6 & Motor off push button (S2) & I 0.5 \\
\hline 7 & Open drain valve manually push button (S3) & I 0.6 \\
\hline 8 & Close drain valve manually push button (S3) & I 0.7 \\
\hline 9 & Drain valve open feedback & I 1.0 \\
\hline
\end{tabular}

Tabel 3.Alamat Analog Input PLC

\begin{tabular}{clc}
\hline No & Deskripsi Digital Input & Alamat \\
\hline 1 & Motor on command (K1) & Q 0.0 \\
\hline 2 & Drain valve open close command & Q 0.1 \\
\hline 3 & Lampu tanda sistem healthy (H1) & Q 0.2 \\
\hline 4 & Lampu tanda drain valve open (H3) & Q 0.3 \\
\hline 5 & Lampu tanda drain valve open (H3) & Q 0.4 \\
\hline
\end{tabular}

Tabel 3. Alamat Digital Input PLC

\begin{tabular}{cll}
\hline No & Deskripsi Digital Input & Alamat \\
\hline 1 & Pressure transmitter - PIT 34121 & IW 288 \\
\hline 5 & Pressure transmitter - PIT 34120 & IW 290 \\
\hline
\end{tabular}

Adapun Koneksi PLC dengan Beberapa Komponen Pendukungnya dapat dilihat pada gambar 4 berkut. 


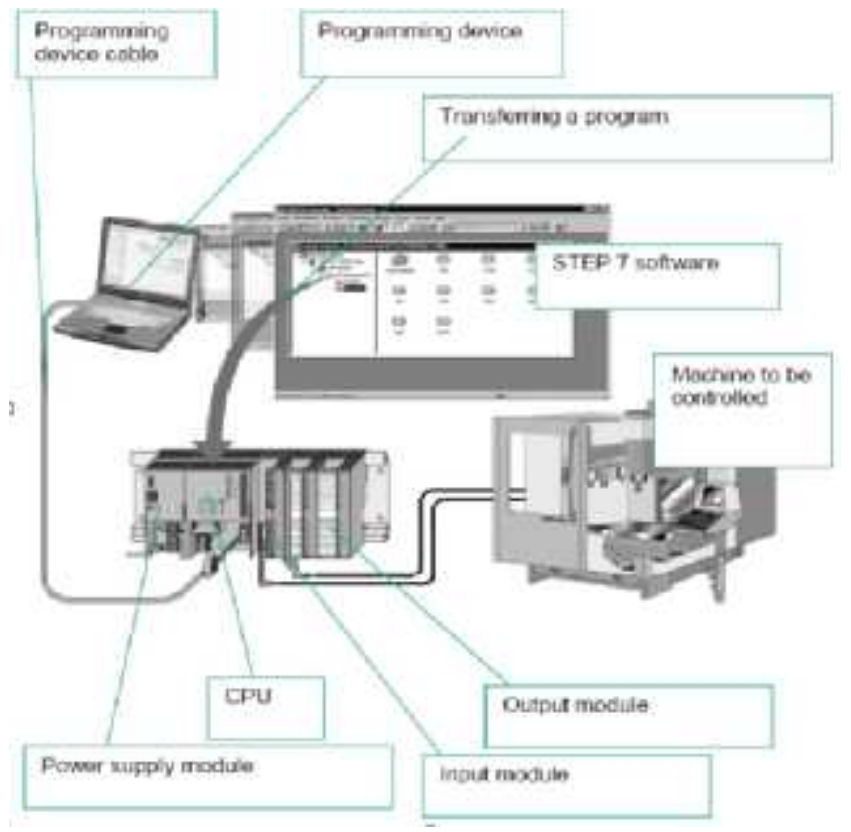

Gambar 4 Koneksi PLC dengan komponen pendukungnya

\section{Hasil Penelitian}

Sistem kontrol menggunakan PLC ini terdiri dari 5 network yang diprogram di Function 1. Network 1 merupakan sistem interlock atau syarat mutlak untuk menjalankan filter weak ammonium nitrate solution. Syarat ini antara lain MCB 3 fasa harus on, emergency switch harus pada posisi release dan thermal overload relai motor tidak trip. Pada saat simulasi, inputan diberikan dengan cara memberikan tanda force input $(\sqrt{ })$ pada alamat I 0.0 , I 0.1 dan I 0.2. Pada kondisi aktual, inputan akan latching ketika semua komponen diposisikan on. Perhatikan tabel 4 berikut

Tabel 4 Kondisi aktual pada saat ready system

\begin{tabular}{|c|c|c|c|c|c|c|c|c|}
\hline \multirow{2}{*}{$\begin{array}{l}\text { Digital } \\
\text { input }\end{array}$} & \multirow{2}{*}{$\begin{array}{l}\text { Digital } \\
\text { Output }\end{array}$} & \multicolumn{2}{|c|}{$\mathrm{P}(\mathrm{kPa} \mathrm{g})$} & \multicolumn{2}{|c|}{ Status } & \multicolumn{2}{|c|}{$\begin{array}{c}\text { Kondisi } \\
\text { Sinyal }\end{array}$} & \multirow{2}{*}{$\begin{array}{c}\text { Tegangan } \\
\text { ukuran }\end{array}$} \\
\hline & & $\geq 30$ & $\leq 10$ & On & Off & 1 & 0 & \\
\hline M 0.0 & - & - & - & $\sqrt{ }$ & - & $\sqrt{ }$ & - & $24 \mathrm{VDC}$ \\
\hline I 0.3 & - & - & - & $\sqrt{ }$ & - & $\sqrt{ }$ & - & $24 \mathrm{VDC}$ \\
\hline MW 3 & - & $\sqrt{ }$ & - & $\sqrt{ }$ & - & $\sqrt{ }$ & - & - \\
\hline- & Q 0.0 & - & - & $\sqrt{ }$ & - & $\sqrt{ }$ & - & $24 \mathrm{VDC}$ \\
\hline- & Q 0.3 & - & - & $\sqrt{ }$ & - & $\sqrt{ }$ & - & $24 \mathrm{VDC}$ \\
\hline MW 3 & - & - & $\sqrt{ }$ & - & $\sqrt{ }$ & - & $\sqrt{ }$ & - \\
\hline- & Q 0.0 & - & - & - & $\sqrt{ }$ & - & $\sqrt{ }$ & $0 \mathrm{VDC}$ \\
\hline- & Q 0.3 & - & - & - & $\sqrt{ }$ & - & $\sqrt{ }$ & $0 \mathrm{VDC}$ \\
\hline
\end{tabular}

Ketika semua syarat ini terpenuhi maka sistem dalam keadaan siap untuk dioperasikan atau ready system sudah terpenuhi sehingga memory bit 0.0 (M 0.0) dan digital output 0.2 (Q 0.2) akan latching, untuk selanjutnya memory bit (M 0.0) ini akan digunakan sebagai interlock untuk menjalankan fase cleaning dan flushing.
Pada network 2, filter akan melakukan fase cleaning. Syarat untuk menjalankan fase cleaning ini adalah memory bit 0.0 ( M 0.0 ) sudah on dan selector switch pada salah satu pilihan yaitu auto atau manual ( I 0.3 ). Pada saat auto, fase ini akan mulai berjalan apabila differential pressure (memory word 3) pada sisi inlet dan outlet vessel filter telah mencapai 
minimal $30 \mathrm{kPa}$ g ditandai dengan motor gear filter akan running secara otomatis. Motor ini akan otomatis berhenti ketika differential pressure sudah mencapai minimal $10 \mathrm{kPa}$, hal ini menandakan bahwa filter sudah bersih.
Pada saat manual, motor gear filter akan running dengan menekan tombol push button motor on ( I 0.4 ) dan motor akan berhenti dari push button motor off ( I 0.5 ). Kondisi yang dimaksud dapat dilihat pada tabel.

Tabel 5 Kondisi Aktual pada Saat Cleaning Auto Operasi

\begin{tabular}{ccccccc}
\hline \multirow{2}{*}{$\begin{array}{c}\text { Digital } \\
\text { input }\end{array}$} & $\begin{array}{c}\text { Digital } \\
\text { Output }\end{array}$ & \multicolumn{2}{c}{ Status } & \multicolumn{2}{c}{$\begin{array}{c}\text { Kondisi } \\
\text { Sinyal }\end{array}$} & \multirow{2}{*}{$\begin{array}{c}\text { Tegangan } \\
\text { ukuran }\end{array}$} \\
\cline { 3 - 6 } & & On & Off & 1 & 0 & \\
\hline 10.0 & - & $\sqrt{n}$ & - & $\sqrt{ }$ & - & $24 \mathrm{VDC}$ \\
10.1 & - & $\sqrt{ }$ & - & $\sqrt{ }$ & - & $24 \mathrm{VDC}$ \\
10.2 & - & $\sqrt{ }$ & - & $\sqrt{ }$ & - & $24 \mathrm{VDC}$ \\
- & M 0.0 & $\sqrt{ }$ & - & $\sqrt{ }$ & - & $24 \mathrm{VDC}$ \\
- & Q 0.2 & $\sqrt{ }$ & - & $\sqrt{ }$ & - & $24 \mathrm{VDC}$ \\
\hline
\end{tabular}

Tabel 6 Kondisi Aktual pada SAAT Scleaning Manual Operasi

\begin{tabular}{ccccccccc}
\hline \multirow{2}{*}{$\begin{array}{c}\text { Digital } \\
\text { input }\end{array}$} & $\begin{array}{c}\text { Digital } \\
\text { Output }\end{array}$ & $\mathrm{P}(\mathrm{kPa})$ & \multicolumn{2}{c}{$\begin{array}{c}\text { I Cycle } \\
\text { Status } \\
\text { Cleaning }\end{array}$} & \multicolumn{2}{c}{$\begin{array}{c}\text { Kondisi } \\
\text { Sinyal }\end{array}$} & $\begin{array}{c}\text { Tegangan } \\
\text { ukuran }\end{array}$ \\
\cline { 2 - 7 } & & $\geq 30$ & $\leq 10$ & 1 & 0 & 1 & 0 & \\
\hline M 0.0 & - & - & - & - & - & $\sqrt{ }$ & - & 24 VDC \\
I 0.3 & - & - & - & - & - & $\sqrt{ }$ & - & 24 VDC \\
MW 3 & - & - & $\sqrt{ }$ & - & - & - & - & - \\
MW 5 & - & - & - & $\sqrt{ }$ & - & - & - & - \\
- & Q 0.1 & - & - & - & - & $\sqrt{ }$ & - & 24 VDC \\
- & Q 0.4 & - & - & - & - & $\sqrt{ }$ & - & 24 VDC \\
\hline
\end{tabular}

Ladder diagram pada network 3 hanya berfungsi pada saat selector switch pada posisi auto saja. Filter akan memberikan sinyal 1 cycle status cleaning sudah terpenuhi dan selanjutnya akan memberikan trigger untuk melakukan auto flushing. Ketika auto selector switch aktif dan motor gear filter running maka status 1 akan berpindah ke memory word 5 ( MW 5). Status 1 cycle cleaning akan reset pada saat fase drain/ flushing sudah selesai ditandai dengan memory word 5 ( MW 5) bernilai 0 .
Network 5 adalah fase drain/ flushing filter weak ammonium nitrate solution. Fase drain/ flushing dapat berlangsung secara auto maupun manual. Pada saat auto, syarat 1 cycle status harus terpenuhi terlebih dahulu dan fase drain/ flushing ini ditandai dengan terbukanya drain valve selama 7 detik. Sedangkan pada saat manual, fase drain/ flushing dilakukan dengan menekan tombol open valve push button ( I 0.6 ). Perhatikan tabel 7 
Tabel 7 Kondisi aktual pada saat drain/flushing auto operasi

\begin{tabular}{ccccccccc}
\hline \multirow{2}{*}{$\begin{array}{c}\text { Digital } \\
\text { input }\end{array}$} & $\begin{array}{c}\text { Digital } \\
\text { Output }\end{array}$ & \multicolumn{2}{c}{$\mathrm{P}(\mathrm{kPa})$} & \multicolumn{2}{c}{ Status } & \multicolumn{2}{c}{$\begin{array}{c}\text { Kondisi } \\
\text { Sinyal }\end{array}$} & $\begin{array}{c}\text { Tegangan } \\
\text { ukuran }\end{array}$ \\
\cline { 3 - 8 } & 230 & $\leq 10$ & On & Off & 1 & 0 & \\
\hline M 0.0 & - & - & - & $\sqrt{ }$ & - & $\sqrt{ }$ & - & 24 VDC \\
I 0.3 & - & - & - & - & $\sqrt{ }$ & - & $\sqrt{ }$ & 24 VDC \\
MW 3 & - & $\sqrt{ }$ & - & $\sqrt{ }$ & - & $\sqrt{ }$ & - & - \\
I 0.4 & - & - & - & $\sqrt{ }$ & - & $\sqrt{ }$ & - & 24 VDC \\
I 0.5 & - & - & - & - & $\sqrt{ }$ & - & $\sqrt{ }$ & 0 VDC \\
- & Q 0.0 & - & - & $\sqrt{ }$ & - & $\sqrt{ }$ & - & 24 VDC \\
- & Q 0.3 & - & - & $\sqrt{ }$ & - & $\sqrt{ }$ & - & 24 VDC \\
\hline
\end{tabular}

Tabel 3 Kondisi aktual pada saat scleaning manual operasi

\begin{tabular}{ccccccccc}
\hline $\begin{array}{c}\text { Digital } \\
\text { input }\end{array}$ & $\begin{array}{c}\text { Digital } \\
\text { Output }\end{array}$ & P (kPa g) & $\begin{array}{c}\text { I Cycle } \\
\text { Status } \\
\text { Cleaning }\end{array}$ & $\begin{array}{c}\text { Kondisi } \\
\text { Sinyal }\end{array}$ & $\begin{array}{c}\text { Tegangan } \\
\text { ukuran }\end{array}$ \\
\cline { 2 - 7 } & & $\geq 30$ & $\leq 10$ & 1 & 0 & 1 & 0 & \\
\hline M 0.0 & - & - & - & - & - & $\sqrt{ }$ & - & 24 VDC \\
I 0.3 & - & - & - & - & - & $\sqrt{ }$ & - & 24 VDC \\
MW 3 & - & - & $\sqrt{n}$ & - & - & - & - & - \\
MW 5 & - & - & - & $\sqrt{ }$ & - & - & - & - \\
I 0.6 & - & - & - & - & - & $\sqrt{ }$ & - & 24 VDC \\
- & Q 0.1 & - & - & - & - & $\sqrt{ }$ & - & 24 VDC \\
- & Q 0.4 & - & - & - & - & $\sqrt{ }$ & - & 24 VDC \\
\hline
\end{tabular}

\section{Kesimpulan}

Hasil penelitian menunjukkan bahwa (1) investigasi terhadap kegagalan eksisting sistem kontrol disebabkan karena terputusnya sequence kerja filter pada saat auto dan tidak adanya feedback differential pressure yang dimasukkan dalam sistem interloc, dan (2) Hasil analisa perbaikan eksisting sistem kontrol adalah penggantian pressure gauge dengan pressure transmitter dan merancangan sistem kontrol baru menggunakan PLC. Sehingga dari hasil analisa perbaikan ini dapat mengatasi kegagalan sistem kontrol lama yaitu dapat melakukan sequence kerja filter secara keseluruhan mulai dari filtering, cleaning dan draining/ flushing baik pada saat auto maupun manual.

\section{Saran}

Saran yang dapat diberikan diantaranya (1) Sistem kontrol hasil modifikasi menggunakan PLC dapat dikoneksikan dengan Distributed Control System di Control Room untuk memonitor urutan kerja filter, memudahkan pengontrolan dan pengambilan data-datanya baik berupa kondisi logic, alarm maupun trending, (2) Perlu adanya update diagram kontrol terhadap adanya perubahan sistem kontrol untuk kepentingan maintenance dan repair (3) Diperlukan perencanaan penggantian manual valve inlet dan valve outlet vessel filter yang dimasukkan pada auto sequence kerja filter untuk memudahkan pengontrolan.

\section{Daftar Pustaka}

[1] I. PT. Kaltim Nitrate, UHDE Operating Instruction Manual of the plant, UD-VT-DC00003 \& UD-VT-DC-00004. 2008.

[2] M. I. Filtration, Operation Instruction Automatic Metal Edge Filter with Radial Scapper Cleaning. PT. Hydromatik Tekhnologi, 2010.

[3] C. E. Yokogawa, "EJX510A \& EJX530A Absolute and Gauge Pressure Transmitter," 27th ed., Tokyo, 2016.

[4] Siemens, "S7-300 Manual \& Module Data," 2013. 